\title{
Cataract development and outcome of surgery in bone marrow transplanted children
}

\author{
B M Calissendorff, P Bolme
}

\begin{abstract}
Cataract development in bone marrow transplanted (BMT) patients was studied prospectively. There were 61 children, transplanted before the age of 18 years, who survived more than 1 year after transplantation. Patients transplanted for leukaemia $(n=43)$ were conditioned before BMT with cyclophosphamide (Cy) and total body irradiation (TBI). Patients with severe aplastic anaemia $($ SAA $)(n=9)$ only received $\mathrm{Cy}$. None of the patients with SAA developed cataracts. All children with leukaemia, who were followed for at least 3 years $(n=37)$, developed lens posterior subcapsular cataracts (PSC). Cataract extraction was performed in 28 eyes, on average $5 \cdot 1$ years (range 3-9 years) after BMT. Postoperative corrected visual acuity was similar to that before BMT. The majority of cases needed laser capsulotomy within 2 years after cataract extraction. TBI seems to be the main cause for the high incidence of cataract after BMT. A relationship to steroid administration could not be proved, but a contributory effect is not excluded.
\end{abstract}

(Br F Ophthalmol 1993; 77: 36-38)

Bone marrow transplantation (BMT) is an established treatment for severe aplastic anaemia (SAA), haematological malignancies, and several hereditary, metabolic, or haemoglobin defect diseases.' At Huddinge University Hospital BMT has been performed routinely since the late 1970s.

Patients are prepared for BMT ('conditioned') in different ways depending on the disease. ${ }^{1}$ The conditioning treatment consists of a cytostatic drug, cyclophosphamide (Cy), and, in all cases of leukaemia, total body irradiation (TBI).

The patients with leukaemia were also treated with different cytostatic drugs, sometimes with irradiation to the head and spine and, in many cases, with steroids in order to achieve remission of their leukaemia before BMT can be performed. Furthermore, many of the patients may be treated with steroids after BMT because of the immunological complication graft versus host disease (GVHD).

Irradiation, cytostatic drugs, and steroids induce lens opacification. The purpose of this study was to investigate prospectively the development of cataract and outcome of cataract surgery in BMT patients.

\section{Patients and methods}

During 1978-89, allogeneic BMTs were performed in 99 patients younger than 18 years of age at Huddinge University Hospital. All patients were examined in a prospective study at the ophthalmic department.

This study was restricted to patients who survived more than 1 year after BMT with a functioning graft. There were 61 patients, 39 male and 22 female. Forty three patients had acute or chronic leukaemia, nine had SAA, and nine had other diseases (three Gaucher's disease, two severe immune deficiency, one Fanconi's anaemia, one thalassaemia, one metachromatic leucodystrophy, and one neuroblastoma). Mean observation time after transplantation was 5 years (range 1-10). Mean age at the time of transplantation was $9 \cdot 5$ years (range 1-17). Baseline data for the different subgroups are summarised in Table 1.

Before BMT, patients with SAA were conditioned with cyclophosphamide (Cy), $50 \mathrm{mg} / \mathrm{kg}$ body weight (bw), for 4 days, whereas patients with malignancies received $\mathrm{Cy}, 60 \mathrm{mg}$ / $\mathrm{kg}$ bw for 2 days followed by TBI, $10 \mathrm{~Gy}$ (except for the lungs, which were shielded to receive no more than $9 \mathrm{~Gy}$ ). TBI was delivered by a linear accelerator at a mean dose of $0.04 \mathrm{~Gy} / \mathrm{min}$. Modifications of the conditioning schedule, used in the group with other diagnoses, always excluded irradiation of an unshielded eye. ${ }^{2}$ Patients with haematological malignancies had always received different regimens of cytostatic drugs and steroids, and in some cases even irradiation to the head before they underwent BMT.

All patients were prophylactically treated with methotrexate and/or cyclosporin for at least 3 months after BMT to avoid GVHD. Many of the patients were also treated with steroids after BMT because of GVHD.

At the ophthalmic department, the patients were examined for lens opacification at regular intervals: before transplantation, after 3, 6, and 12 months, and then once a year. The examinations included visual acuity (VA), slit-lamp examination including transillumination through dilated pupils, and ophthalmoscopy. In cases where surgical intervention was necessary, extracapsular cataract extraction (ECCE) was performed, sometimes with implantation of an

Table 1 Characteristics of the BMT patients who survived 1 year or more

\begin{tabular}{|c|c|c|c|c|}
\hline & Leukaemia & $\begin{array}{l}\text { Aplastic } \\
\text { anaemia }\end{array}$ & Other & Total \\
\hline $\begin{array}{l}\text { Number } \\
M / F \\
\text { Age (years) at BMT. }\end{array}$ & $\begin{array}{l}43 \\
25 / 18\end{array}$ & $\begin{array}{l}9 \\
8 / 1\end{array}$ & $\begin{array}{l}9 \\
5 / 4\end{array}$ & $\begin{array}{l}61 \\
39 / 22\end{array}$ \\
\hline $\begin{array}{l}\text { mean } \\
\text { range }\end{array}$ & $\begin{array}{l}10 \cdot 0 \\
1-17\end{array}$ & $\begin{array}{l}11 \cdot 3 \\
2-17\end{array}$ & $\begin{array}{l}5 \cdot 3 \\
2-10\end{array}$ & $\begin{array}{l}9 \cdot 5 \\
1-17\end{array}$ \\
\hline $\begin{array}{l}\text { Observation time (years } \\
\text { mean } \\
\text { range }\end{array}$ & $\begin{array}{l}5 \cdot 4 \\
1-10\end{array}$ & $\begin{array}{l}5 \cdot 4 \\
1-10\end{array}$ & $\begin{array}{l}3 \cdot 3 \\
1-8\end{array}$ & $\begin{array}{l}5 \cdot 1 \\
1-10\end{array}$ \\
\hline
\end{tabular}


Figure 1 Formation of cataract in relation to time. Distribution of newly discovered lens opacifications (1st obs. cat) and opacifications already seen at previous examinations (establ. cat).

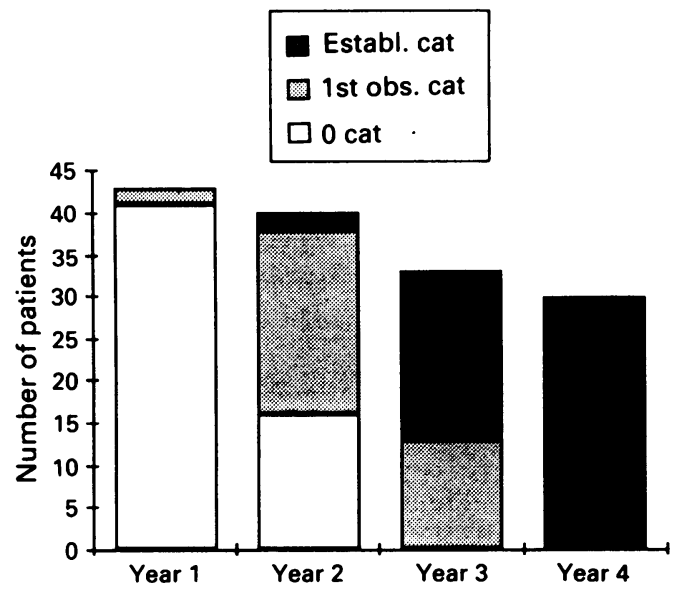

intraocular lens. At the end of the operation a subconjunctival injection of gentamicin was given. Topical steroids were routinely administered, and in some cases topical antibiotics were added.

YAG-laser capsulotomy was performed in patients with secondary cataract.

\section{Results}

None of the patients treated for aplastic anaemia developed cataracts whereas all patients in the leukaemia group had lens changes within 3 years after transplantation. There was no correlation between cataract development and type or intensity of treatment of the leukaemia before BMT.

Figure 1 illustrates the development of cataract in the leukaemia group. In two cases, lens changes were seen at the 1 year follow up. At the 2 year control, 22 new cases were found, and at the 3 year control, all remaining patients in this group had clearly visible lens opacifications.

In the group with 'other' diagnoses, only one of the four patients observed for 3 years or more showed lens changes. This case was a patient with Fanconi's anaemia who at the 4 year examination displayed lens opacities. The patient with the longest observation time in this group had clear lenses even 8 years after BMT.

The lens changes were all of the posterior subcapsular type (PSC), sometimes with additional small vacuoles. In spite of the PSC, VA was often good, but the patients usually complained of glare. The reduction in VA seemed to be most pronounced between years 2 and 4 (Fig 2). Patients with fairly well preserved VA at

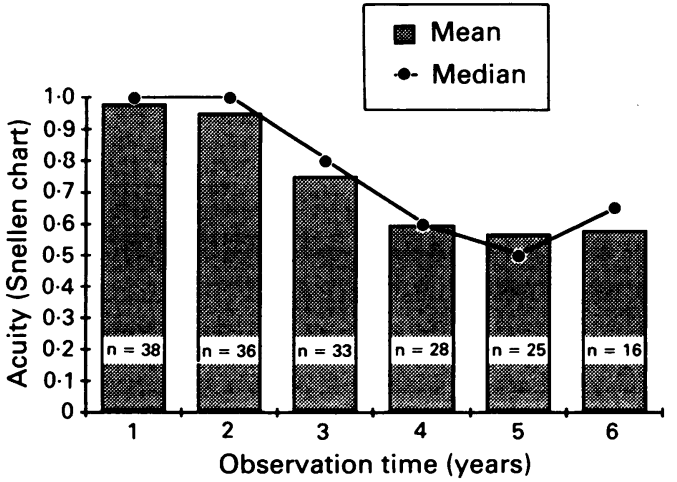

Observation time (years) the 5 year control lost only 1-2 Snellen lines of acuity during the following years.

In 28 eyes of 17 patients, VA deteriorated to a level where cataract surgery was indicated. Cataract surgery on the first eye was performed at an average of 5.1 years after BMT (range 3-9 years). Surgery was sometimes postponed by patient request. The VA in the majority of cases ran more or less parallel in both eyes, but in two cases reduction of VA led to cataract extraction on one eye while fairly good VA remained on the other $(0.8$ and 0.7 respectively, 9 and 8 years after transplantation).

Cataract extraction was performed by extracapsular technique. Five cases with pronounced keratoconjunctivitis sicca (KCS) had implantation of an intraocular lens (IOL). The cataract changes were usually adherent to the posterior lens capsule. In most cases it was impossible to clean the capsule without risking breakage. In spite of remnants on the posterior capsule initial postoperative VA was often surprisingly good. However in the majority of cases laser capsulotomy became necessary within 2 years after cataract extraction. Follow up time after cataract surgery varied from 1 to 4 years. Final visual outcome was good. All patients achieved corrected VA similar to pretreatment levels (before BMT). Contact lens wearing was possible for all patients not given IOLs in spite of mild symptoms of KCS in a couple of cases. In the cases with IOLs, the implants have been well tolerated and the operations have not exacerbated the KCS.

No cases of postoperative infections or other serious complications were seen. One case, a girl with herpetic retinal scars, had her cataract extraction performed while undergoing systemic acyclovir treatment. In some cases, the surgeon had the impression that patients had a greater tendency to bleed than ordinary cataract patients. However, this bleeding did not influence the outcome.

\section{Discussion}

Cataract development in BMT patients has been described in many reports. ${ }^{3-6}$ The incidences vary somewhat depending on follow up time and classification of the material. Livesey et $a l^{+}$ reported a cataract frequency of $83 \%$ after TBI treatment in one session. Deeg et $\mathrm{al}^{3}$ found that $80 \%$ of the patients receiving single dose TBI developed cataracts whereas the incidence with fractionated TBI or with only chemotherapy was less than $20 \%$. Hoover et al found PSC in $52 \%$ of irradiated patients but none in patients who were not irradiated. In our material, comprising all transplanted patients irrespective of follow up time, $57 \%$ showed lens opacifications. Three years after BMT the incidence had risen to $77 \%$, while in the leukaemia subgroup, where all patients had received TBI, the frequency was $100 \%$. Elliott et $a l^{8}$ in their study of childhood leukaemia found a cataract frequency of only $12 \%$. They also found that boys were more severely affected than girls. Though in our study lens opacities were observed a little earlier in boys than in girls (mean $2 \cdot 1$ and 2.5 years respectively), this difference was not statistically
Figure 2 Reduction of visual acuity (Snellen lines) with time in the leukaemia group (right eye). 
significant; nor was there any difference between sexes in development and degree of opacification.

Multiple cataractogenic factors are involved in BMT. Radiation as a cause of cataract formation has been known for almost a century. In 1957 Merriam and Focht ${ }^{9}$ presented a clinical study of radiation cataract and the relationship to dose. Black et $a l^{10}$ proposed a relationship between systemic corticosteroid and cataract formation which has since been proved in many studies. ${ }^{112}$ Ocular side effects from chemotherapeutic agents are also reported. ${ }^{13}$

The results from our study point to radiation as the predominant cause of cataract. Though other cataractogenic factors in the treatment may have additive or synergistic effects, the material is too small to prove any such influence. Thus, it was not possible to note that patients who had received steroids and/or irradiation to the head before BMT, developed cataract earlier than those leukaemia patients not treated before BMT with these cataractogenic factors. The three patients with chronic myeloid leukaemia had comparatively low doses of cytostatic drugs before BMT but developed cataract within 3 years. Steroid treatment for GVHD was as frequent in the SAA group as in the leukaemia group but cataract was only found in the latter.

Biological variability could explain the disparity of cataract development between patients with similar treatments. The energy which reaches the eye from identical TBI doses is very difficult to calculate and probably differs between individuals and perhaps even between eyes of the same individual. This variability could account for unequal cataract progression which, in two cases, led to cataract extraction from one eye while the other still had good visual acuity many years later.

Cataract surgery was necessary in 17 of the 38 cases with verified lens opacification. This figure will certainly increase with time. Surgery was performed at a median of 5 years after transplantation. This was a little later than in our study of adult BMT patients, where the mean for cataract surgery was $4 \cdot 1$ years post BMT. Livesey $e t a l^{4}$ reported a median for surgery of 6 years after BMT in their patients aged 12-61 years. From these figures it is not possible to tell if a young lens is either more susceptible or more refractive to the effects of irradiation. Indications for cataract surgery vary among different centres and are not always the same for children as for adults. Early surgery in a child might be necessary to prevent amblyopia, while later in childhood one is inclined to postpone cataract surgery in order to preserve accommodation for as long as possible.

Intraocular lens implantation in children is controversial. Because of the rapid change in refraction in early childhood and the unknown long term effects of IOL implantation, many surgeons prefer a simple extracapsular extraction, especially since contact lens use has a high acceptance in that age group. Because BMT patients have a high frequency of keratoconjunctivitis sicca, ${ }^{5}$ the option of contact lens use is sometimes excluded. In the majority of cases we performed an extracapsular extraction without implantation. However, dry eye syndrome was the reason why five of the patients received an intraocular lens. These five patients had constant subjective symptoms, and showed at each examination marked staining of the cornea and clinically visible unstable tear films as assessed by tear break-up time.

The pronounced need for YAG-laser capsulotomy was not necessarily a consequence of the primary disease or its treatment, given that younger persons have a much greater tendency to develop secondary cataracts. ${ }^{1+}$

The high incidence of cataract development in children undergoing BMT shows the necessity for a continuing ophthalmic follow up of these patients. The risk of amblyopia is great especially in young children; here early surgery and correction are associated with better visual outcome.

Because of the late side effects caused by conditioning treatment with $\mathrm{TBI}^{2}{ }^{15}$ many groups have changed to a fractionated radiation. This has resulted in lower frequency of cataracts, ${ }^{3}$ though the short follow up time in some of these studies does not permit decisive conclusions as to cataract development in the long run.

We have started a prospective study comparing our original conditioning procedure using TBI with one exchanging radiation with busulphan (5 $\mathrm{mg} / \mathrm{kg} /$ day for 4 days). Time will show if this conditioning treatment will give better results, taking both survival and side effects into consideration.

1 Storb R, Thomas ED. Allogeneic bone marrow transplantation. Immunol Rev 1983; 71: 77-102.

2 Ringdén $\mathrm{O}$, Bolme $\mathrm{P}$, Lönnqvist $\mathrm{B}$, Tollemar B, Dahllöf $\mathrm{G}$ Gahrton $\mathrm{G}$, et al. Bone marrow transplantation in children. Clin Transplant 1989; 3: 12-8.

3 Deeg HJ, Flournoy N, Sullivan KM, Sheehan K, Buckner CD, Sanders E, et al. Cataract after total body irradiation and marrow transplantation. Int $\mathcal{F}$ Radiat Oncol Biol Phys 1984; 10: $957-64$.

4 Livesey SJ, Holmes JA, Whittaker JA Ocular complication of bone marrow transplantation. Eye 1989; 3: 271-6.

5 Calissendorff B, Bolme P, el Azazi M. The development of cataract in children as a late side-effect of bone marrow transplantation. Bone Marrow Transplant 1991; 7: 427-9.

6 Bray LC, Carey PJ, Proctor SJ, Evans RGB, Hamilton PJ. Ocular complications of bone marrow transplantation. $\mathrm{Br} \mathcal{J}$ Ophthalmol 1991; 75: 611-4.

7 Hoover DL, Smith LEH, Turner SJ, Gelber RD, Sallan SE Ophthalmic evaluation of survivors of acute lymphoblastic leukemia. Ophthalmology 1988; 95: 151-5,

8 Elliot AJ, Oakhill A, Goodman S. Cataracts in childhood leukaemia. BrF Ophthalmol 1985; 69: 459-61.

9 Merriam GR, Focht EF. A clinical study of radiation cataracts and the relationship to dose. Am 7 Roentgen 1957; 77: 75985

10 Black RR, Oglesby RB, von Sallman L, Bunim JJ. Posterio subcapsular cataracts induced by corticosteroids in patient with rheumatoid arthritis. FAMA 1960; 174: 166-71.

11 Crews SJ. Posterior subcapsular lens opacities in patients on long term corticosteroid therapy. BMF 1963; iv: 1644-7.

12 Urban RL, Cotlier E. Corticosteroid-induced cataracts. Jurg Ophthalmol 1986; 31: 102-10.

13 Fraunfelder FT, Meyer SM. Ocular toxicity of antineoplastic agents. Ophthalmology 1983; 90: 1-3.

14 Keech RV, Tongue AC, Williams ES. Complications after surgery for congenital and infantile cataracts. Am $\mathcal{J}$ Ophthat mol 1989; 108: $136-41$.

15 Deeg HJ, Storb R, Thomas ED. Bone marrow transplantation: a review of delayed complications. Br F Haematd 1984; 57 : a review of 